\title{
Advancing gynecologic oncology in Latin America through Project ECHO
}

\author{
Melissa Lopez Varon (D) , Houston, USA; Ellen Baker, Houston, USA; Erick Estuardo Estrada, Guatemala City, \\ Guatemala; Kathleen M Schmeler, Houston, USA and Rene Pareja, Medellin, Colombia
}

It is estimated that there will be 2523200 new cases of cancer in Latin America in 2040 , a $79 \%$ increase over current numbers. ${ }^{1}$ This is especially concerning when considering the scarce human resources in some low resource countries in the region. For example, there are 3.1 physicians per 10000 people in Honduras, a low-income country, compared with 50.4 physicians per 10000 people in Uruguay, a high-income country. ${ }^{2}$ The disparity in infrastructure and resources between these two countries is further highlighted by the fact that the projected total number of cancer cases for both countries is estimated to be similar in 2040; 20452 new cancer cases in Honduras and 19563 in Uruguay. ${ }^{1}$ This high variability of available medical infrastructure, resources and expertise in the region highlights the importance of collaborative efforts among low- and high-income countries in Latin America to work together to reduce these disparities and improve access to quality care.

The University of Texas MD Anderson Cancer Center (MD Anderson) is the largest cancer center in the USA. MD Anderson offers observerships for doctors from the Latin American region to spend 1 to 3 months with gynecologic oncology specialists. These short-term visits include observing in clinic and the operating room as well as learning about research and clinical trials. Strong professional collaborations often develop between the hosting and visiting doctors. Over the last several years, many collaborative projects related to training, education and international research have developed between the MD Anderson faculty and gynecologic oncologists in Latin America. One of the challenges to sustain these joint efforts are the high costs and logistical difficulties for individuals to travel between institutions for in-person meetings on a regular basis. This is especially relevant during the ongoing COVID-19 pandemic.
One innovative model to overcome the challenges of international collaboration and to keep the partnerships active is the use of the Project ECHO (Extension for Community Healthcare Outcomes) model to provide regular communication and continued opportunities for collaboration among partners. Project ECHO was created as a telementoring model to increase local specialty capacity in rural or medically underserved communities. The Project ECHO model uses regularly scheduled videoconferences to connect specialists with local medical providers. The videoconference sessions include casebased discussions similar to a tumor board and are complemented by a short didactic on a related topic. ${ }^{3}$

The Latin America Project ECHO for Management of Gynecologic Cancers started in 2015 as a collaborative project between MD Anderson and Universidad de la Republica in Montevideo, Uruguay. ${ }^{4}$ The Project ECHO sessions are held monthly for 1 hour and are conducted in Spanish via ZOOM (Figure 1). The majority of the meeting time is devoted to case-based presentations from the participants followed by a moderated discussion including bestpractice management, considering the context and resources available. Project ECHO uses a "hub and spoke" model with MD Anderson serving as the hub and institutions in Latin America serving as the spokes. The initial program included physicians from seven countries in Latin America: Mexico, El Salvador, Peru, Uruguay, Paraguay, Colombia, and Guatemala ${ }^{4}$ and was focused on cervical cancer prevention and management. Cervical cancer is the third most common cancer in women in Latin America and is the most common cancer in women in 11 of the 32 countries of the region. ${ }^{56}$ 0 ver the last 5 years, the program has grown and expanded with doctors joining from an additional five countries (Venezuela, Bolivia, Argentina, Brazil, and Ecuador) for a total of 12 participating countries in the region.
In 2018, we partnered with the International Gynecologic Cancer Society (IGCS) to incorporate this program into their global training curriculum and broadened the focus to include all gynecologic cancers. The IGCS Global Curriculum is a comprehensive training program that pairs specialists from higher resource regions with gynecologists in countries which have no formal training program in gynecologic oncology. To date, there are 12 IGCS training programs around the world including one in Guatemala. Mentors for the program include Dr René Pareja (Colombia) and Dr Julio Lau (Guatemala). They work in close collaboration to train the first fellow in the program, Dr Erick Estrada, gynecologist in Guatemala. Of note, Dr Pareja and Dr Estrada were both previous participants in the MD Anderson Observership Program.

Monthly Project ECHO videoconferences are held as virtual tumor boards as part of the larger IGCS fellowship training program. During Project ECHO sessions, Dr Estrada prepares and presents gynecologic oncology cases from his hospital in Guatemala. Following the presentation there is a discussion among specialists from the participating 12 countries in Latin America regarding diagnosis, treatment and management. It is an opportunity for all participants to learn about care of patients across the region, and a great benefit for Dr Estrada and his mentors to receive feedback from many regional experts. Other participants from the region may also present cases, and guest lecturers provide additional updates on best practices including reviewing recent publications.

Since October 2015, we have held 48 Project ECHO-Latin America sessions with an average of 29 participants from 12 countries per session. In these sessions, 62 patient cases have been presented and discussed. In a survey of attendees, $70 \%$ reported adopting best practice care in their daily interactions with patients and $87 \%$ reported an increase 


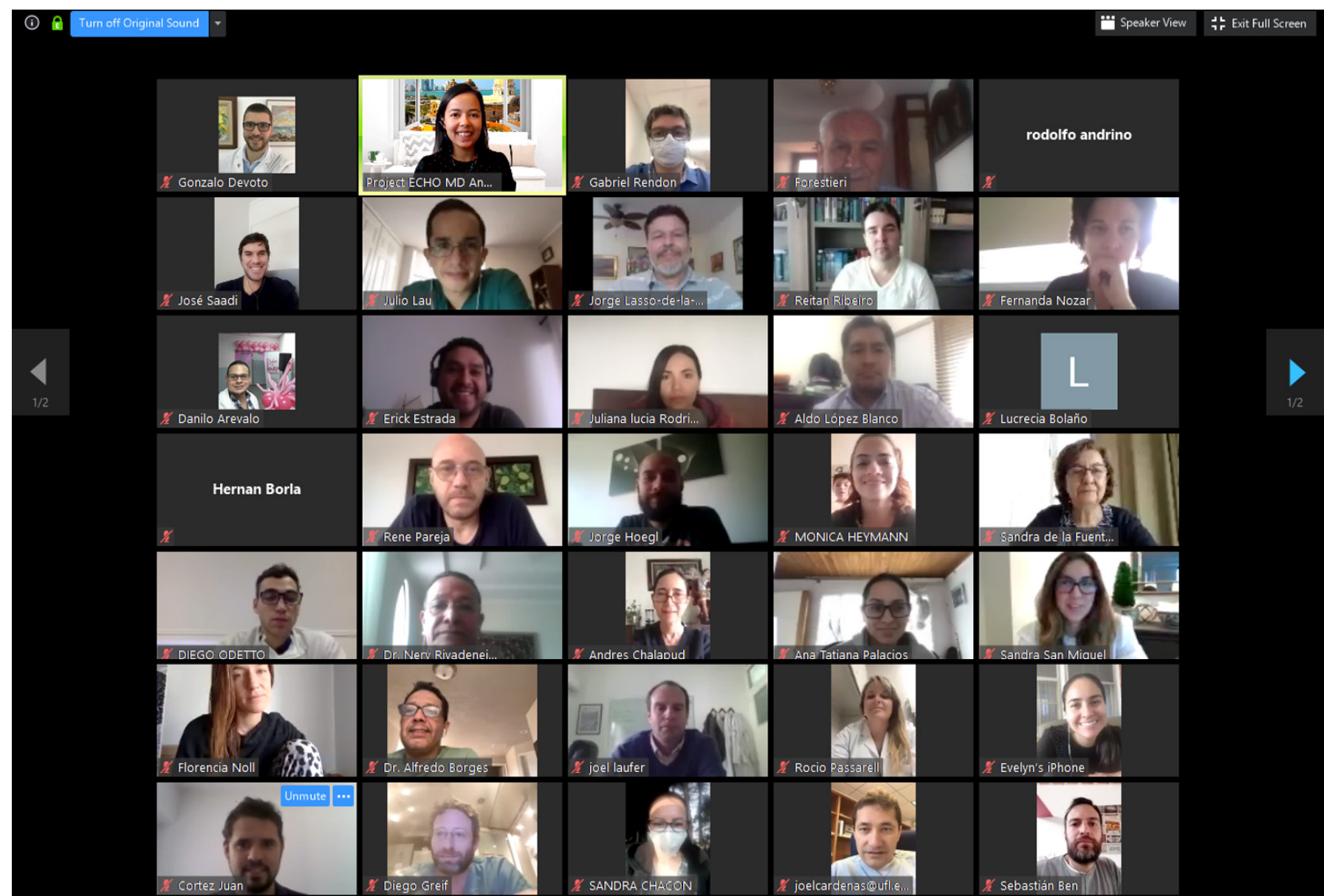

Figure 1 Project ECHO session with participants from Mexico, Uruguay, Paraguay, El Salvador, Peru,Colombia, Argentina and MD Anderson. ECHO, Extension for Community Healthcare Outcomes.

in knowledge due to direct participation in the ECHO sessions.

This initiative continues to grow in the region and participants are enthusiastic to continue to attend the ECHO meetings. This strong network of regional specialists has an opportunity to use these sessions to create and promote evidence-based guidelines and recommendations. They also benefit from the academic nature of the collaborations, and importantly this program provides an opportunity for all participants to improve their skills and knowledge and provide better care for their patients. In addition, it allows a way for collaborators from around the world to stay connected at a time when travel and in-person meetings are restricted.

If you are interested in joining these Project ECHO sessions, please contact ECHOInfo@ mdanderson.org or Melissa Lopez Varon at MSLopez1@mdanderson.org

Correspondence to Melissa Lopez Varon, University of Texas MD Anderson Cancer Center, Houston, TX 77030-4000, USA; MSLopez1@mdanderson.org

\section{Twitter Erick Estuardo Estrada @mderickestrada}

Acknowledgements Mary Eiken, Susan Ralph, and all our Project ECHO Latin America participants and collaborators.

Contributors All authors included in this manuscript have contributed to the work being shared for publication.

Funding The authors have not declared a specific grant for this research from any funding agency in the public, commercial or not-for-profit sectors.

Competing interests None declared.

Patient consent for publication Not required.

Provenance and peer review Not commissioned; internally peer reviewed.

(c) IGCS and ESGO 2020. No commercial re-use. See rights and permissions. Published by BMJ.

A) Check for updates

To cite Varon ML, Baker E, Estrada EE, et al. Int J Gynecol Cancer 2020;30:1840-1841.

Accepted 1 May 2020

Published Online First 9 June 2020

Int J Gynecol Cancer 2020;30:1840-1841 doi:10.1136/ijgc-2020-001559
ORCID iD

Melissa Lopez Varon http://orcid.org/0000-00028960-8017

\section{REFERENCES}

1 International Agency for Research on Cancer. Global cancer observatory. World Health organization, 2018. Available: http:// gco.iarc.fr

2 World Health Organization. Global Health Observatory: Density of physicians (total number per 1000 population): Latest available year [internet. Geneva: WHO, 2018.

3 Arora S, Thornton K, Murata G, et al. Outcomes of treatment for hepatitis $C$ virus infection by primary care providers. $N$ Engl $J$ Med 2011;364:2199-207.

4 Lopez MS, Baker ES, Milbourne AM, et al. Project ECHO: a telementoring program for cervical cancer prevention and treatment in low-resource settings. J Glob Oncol 2017;3:658-65.

5 Pilleron S, Cabasag CJ, Ferlay J, et al. Cervical cancer burden in Latin America and the Caribbean: where are we? Int J Cancer 2020. doi:10.1002/ijc.32956. [Epub ahead of print: 09 Mar 2020].

6 Lopez MS, Baker ES, Maza M, et al. Cervical cancer prevention and treatment in Latin America. J Surg Oncol 2017;115:615-8. 